American Journal of Pharmacology and Toxicology 2 (3):140-145, 2007

ISSN 1557-4962

(C) 2007 Science Publications

\title{
Acute Hypotensive and Diuretic Activities of Chamaemelum nobile Aqueous Extract in Normal Rats
}

\author{
${ }^{1}$ N.A. Zeggwagh, ${ }^{2}$ J.B. Michel and ${ }^{1}$ M. Eddouks \\ ${ }^{1}$ UFR PNPE, BP.21, Errachidia, 52000, Morocco \\ ${ }^{2}$ U460 INSERM, Faculty of Medicine Xavier Bichat, Paris, France
}

\begin{abstract}
This study aims to evaluate the effect of Chamaemelum nobile $(\mathrm{Cn})$ intravenous injection on cardiovascular and renal function of normal rats. Intravenous bolus injection of $\mathrm{Cn}$ at the dose of 50, 100 and $200 \mathrm{mg} \mathrm{kg}^{-1}$, produced dose dependent reduction in arterial blood pressure $(\mathrm{p}<0.001)$. Significant reduction in heart frequency was observed after $\mathrm{Cn}$ injection at a dose of 100 and $200 \mathrm{mg} \mathrm{kg}^{-1}(\mathrm{p}<0.001)$. Perfusion of $\mathrm{Cn}$ aqueous extract at a dose of $200 \mathrm{mg} \mathrm{kg}^{-1} \mathrm{~h}^{-1}$ caused a significant increase in urine output after three hours of perfusion $(p<0.001)$. Significant increase in urinary sodium and potassium excretion was observed from the first $(\mathrm{p}<0.05)$ to the third hour $(\mathrm{p}<0.001)$ of $\mathrm{Cn}$ perfusion. Urinary chlorure excretion increased after two hours of perfusion $(p<0.001)$. However, glomerualr filtration rate remained unchanged after $\mathrm{Cn}$ perfusion $(\mathrm{p}<0.05)$. We conclude that the $\mathrm{Cn}$ aqueous extract possess potent acute hypotensive effect in normal rats. In addition $\mathrm{Cn}$ perfusion may affect renal function to increase urine and electrolytes excretion.
\end{abstract}

Key words: Ethnopharmacology, mean arterial pressure, urine output, urine electrolytes

\section{INTRODUCTION}

Medicinal plants represent a valuable source of new therapeutic agents ${ }^{[1]}$. According to the World Health Organisation, more than $80 \%$ of the world's population-primarily those of developing countriesrelies on plants and plant-derived medicines for their healthcare ${ }^{[2]}$. More than 231 medicinal plants are communally used in the Moroccan pharmacopoea ${ }^{[3]}$. As a part of Moroccan territory, Tafilalet region is a repository of plants in the treatment of cardiovascular diseases $^{[4,5]}$. Increasing urine and electrolytes excretion may be beneficial in the treatment of hypertension ${ }^{[6]}$. Studies have been established the diuretic effect of several plants extract in normal and hypertensive rats $^{[6-14]}$. Furthermore, the observed diuretic activity was associated in several cases with a reduction in arterial blood pressure ${ }^{[15,16]}$.

Chamaemulum nobile $(\mathrm{Cn})$ is a plant belonging to Asteraceae family. The aqueous extract of this plants is used in the treatment of diabetes and cardiovascular diseases $^{[4]}$. To our knowledge, no scientific informations are available concerning the cardiovascular effect of $\mathrm{Cn}$ aqueous extract. This study was carried out to evaluate the effect of intravenous injection of $\mathrm{Cn}$ on arterial blood pressure and renal function in normal rats.

\section{MATERIALS AND METHODS}

Plant material: Specimens of $\mathrm{Cn}$ were collected from the Tafilalet region (semi-arid area) of Morocco in May-June 2003 and air-dried at $40{ }^{\circ} \mathrm{C}$. The plant was previously identified and authenticated by Pr. M. Rejdali (Agronomy and Veterinary Institute, Rabat) and a voucher specimen (ME23) was deposited at the herbarium of the Faculty of Sciences and Techniques Errachidia.

Preparation of the aqueous extract: One $g$ of powdered plant mixed with $100 \mathrm{ml}$ distilled water were boiled for $10 \mathrm{~min}$ and then cooled for $15 \mathrm{~min}$. Thereafter, the aqueous extract was filtered using a Millipore filter (Millipore $0.2 \mathrm{~mm}$, St Quentin en Yvelines, France) to remove particulate matter. The extract was yellow coloured with a percent yield of 14 $\%$, its average osmolarity was $32 \mathrm{mOsm}, \mathrm{pH} 6.3$ and with a very low viscosity. The filtrate was then freezedried and the desired dose (mg of lyophilized aqueous extract of $\mathrm{Cn}$ plant per $\mathrm{kg}$ body weight) was then prepared and reconstituted in physiologic saline solution just before administration..

Animals: The hypotensive and diuretic effect of $\mathrm{Cn}$ aqueous extract was studied in adult male wistar rats weighing (250-300 g) and 6 weeks aged. Animals were

Corresponding Author: Mohamed Eddouks, BP 21, Errachidia, 52000, Morocco Tel: +212 55574497 Fax: +212 55574485 
housed under standard environmental conditions $\left(23 \pm 1^{\circ} \mathrm{C}, 55 \pm 5 \%\right.$ humidity and a $12 \mathrm{~h} \mathrm{light/dark}$ cycle $)$ and had free access to water and ad libitum standard laboratory diet.

Surgery: The rats were anaesthetized by an intraperitoneal injection of Inactin at a dose of $50 \mathrm{mg}$ $\mathrm{kg}^{-1}$ of body weight. They were then placed on a thermostated table to keep them at a constant temperature.

Experimental procedures: Effect of intravenous bolus injection of Cs aqueous extract on MAP and HR.

Arterial blood pressure was measured from the carotide artery via heparinized polyethylene cannula PE-50 connected to a blood pressure transducer Gould Statham transducer allowing the monitoring of blood pressure.

The desired dose of drugs and Cs lyophilized aqueous extract were disolved in a constant volume of saline $200 \mu \mathrm{L}$ and injected in the form of bolus injection via a catheters PE-10 inserted into the external jugular vein followed by a saline flush $(200 \mu \mathrm{L})$. Animals were allowed to equilibrate for at least $30 \mathrm{~min}$ before administration of $\mathrm{Cn}$ aqueous extract.

Six rats received graded doses $(50,100$ and $200 \mathrm{mg} \mathrm{kg}^{-1}$ ) of $\mathrm{Cn}$ aqueous extract which was administered intravenously and the corresponding blood pressure and heart rate were recorded immediately. A control group received bolus intravenous injection of saline 10 min separate each intravenous injection. Mean Arterial Blood Pressure (MAP) is a sum of diastolic blood pressure and $1 / 3$ pulse pressure $(\mathrm{mmHg})$.

Renal effect of $\mathrm{Cn}$ aqueous extract perfusion: Two catheters PE50, one filled with physiological saline solution $(\mathrm{NaCl})$, the other filled with heparinized physiological saline solution were introduced respectively to the right jugular vein of the cardiac side and to the left jugular vein of the encephalic side. The first serves to perfuse the test solutions and the second for blood sampling. The bladder was also catheterized in order to collect urine for determination of different parameters. At the end of the experiment, the animals were sacrificed by cutting their carotids, urine and plasma were conserved at $-20^{\circ} \mathrm{C}$ until biochemical analysis.

The group one served as an untreated control, whereas the second group was given a perfusion of $\mathrm{Cn}$ at a dose of $200 \mathrm{mg} \mathrm{kg}^{-1} \mathrm{~h}^{-1}$. The third group received furosemide, as a reference drug at a dose of
$0.1 \mathrm{mg} \mathrm{kg}^{-1} \mathrm{~h}^{-1}$. The experimental protocol adopted has two phases: A control phase of $30 \mathrm{~min}$ when saline solution was perfused and an experimental phase of four hours for $\mathrm{Cn}$ aqueous extract and furosemide perfusion. Five urine and blood samples were taken; at the start of control phase and within the experimental phase at the start, 1,2 and $3 \mathrm{~h}$ of treatment. All experiments were performed in fasted rats.

Parameters: Blood samples were collected from the jugular vein. Urinary samples were collected from the catheterized bladder. Creatinine was evaluated by colorimetric methods, according to the manufacturer's protocol (Boerhinger, Germany) using a spectrophotometer (HITACHI Model U-2001).

Sodium, potassium and chloride levels were determined in urine samples using an auto-analyser (HITACHI 911-Boehringer).

Glomerular filtration rate was evaluated by the clearance of creatinine.

Statistical analysis: Results were expressed as mean \pm SEM of six observations. ANOVA was used to calculate the levels of significance for comparison made within group and between groups using Graphpad prism 4.0 software.

\section{RESULTS}

Effect of intravenous injection of $\mathrm{Cn}$ aqueous extract on arterial blood pressure: Lyophilized $\mathrm{Cn}$ aqueous extract was injected intravenously at three different doses: $50,100,200 \mathrm{mg} \mathrm{kg}^{-1}$ to anesthetized normal rats. Figure 1 shows, arterial blood pressure evolution after intravenous injection of $\mathrm{Cn}$ aqueous extract. The three used doses produced a significant reduction in arterial blood pressure $2 \mathrm{~min}$ after intravenous injection $(\mathrm{p}<0.001)$. Maximal reduction was observed 2 min after the intravenous injection of $200 \mathrm{mg} \mathrm{kg}^{-1}$ of $\mathrm{CN}$ aqueous extract $(\mathrm{p}<0.001)$. The observed fall in arterial blood pressure disappear progressively causing a return to the baseline values after $10 \mathrm{~min}$ of intravenous injection. However, in the control group, intravenous injection of $200 \mu \mathrm{L}$ of saline solution did not affect arterial blood pressure.

Effect of intravenous injection of $\mathrm{Cn}$ aqueous extract on heart rate: Intravensou injection of $\mathrm{Cn}$ aqueous extract at a dose of 100 and $200 \mathrm{mg} \mathrm{kg}^{-1}$ produced reduction in heart rate with $\mathrm{p}<0.01$ and $p<0.001$ respectively (Fig. 2). No significant change in heart rate was observed after 5 min of $\mathrm{Cn}$ intravenous 


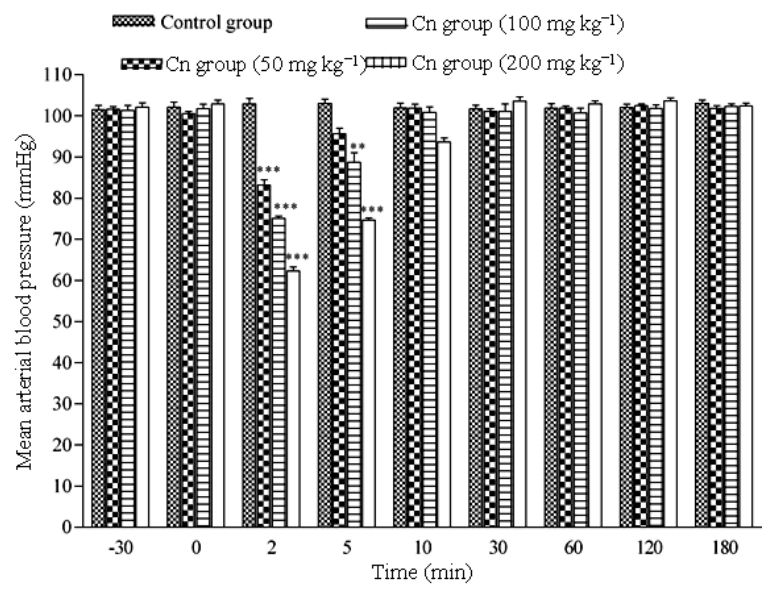

Fig. 1: Effect of bolus intravenous injection of aqueous Cn extract (50, 100 and $200 \mathrm{mg} \mathrm{kg}^{-1}$ ) on arterial blood pressure $(\mathrm{mmHg})$ of anesthetized normal rats

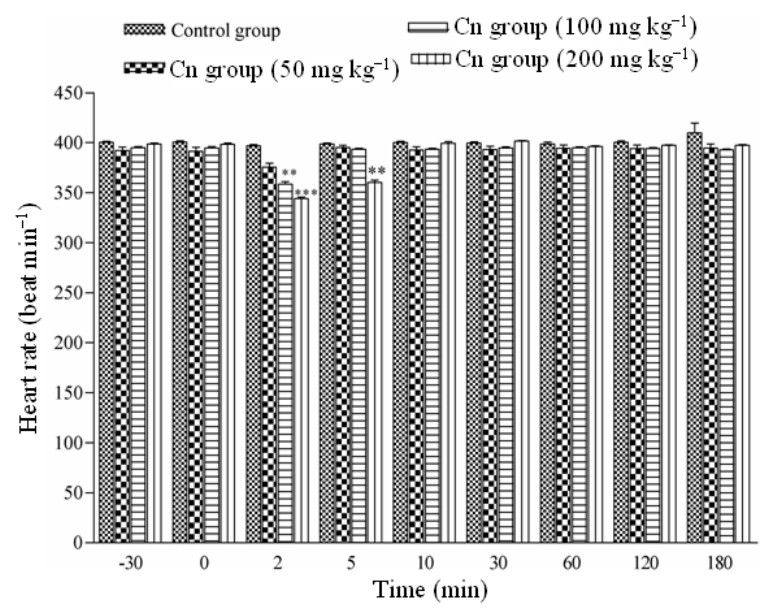

Fig. 2: Effect of bolus intravenous injection of aqueous Cs extract (50, 100 and $200 \mathrm{mg} \mathrm{kg}^{-1}$ ) heart rate (beats $\mathrm{min}^{-1}$ ) of anesthetized normal rats. Data are expressed means \pm SEM, $\mathrm{n}=6$ per group. *: $\mathrm{p}<0.05, * *: \mathrm{p}<0.01, * * *: \mathrm{p}<0.001$

injection. The intravenous injection of $\mathrm{Cn}$ aqueous extract at a dose of $50 \mathrm{mg} \mathrm{kg}{ }^{-1}$ did not significantly affect the heart rate.

Effect on urine output: Intravenous perfusion of $\mathrm{Cn}$ aqueous extract at a dose of $200 \mathrm{mg} \mathrm{kg}^{-1} \mathrm{~h}^{-1}$ produced a significant increase in urine output three hours after the start of perfusion. However, furosemide perfusion significantly increases the urine output after one hour of intravenous perfusion. The increase in urine output was sustained until three hours of perfusion period. No change in the urine output was observed during three hours of intravenous of saline solution (Fig. 3).

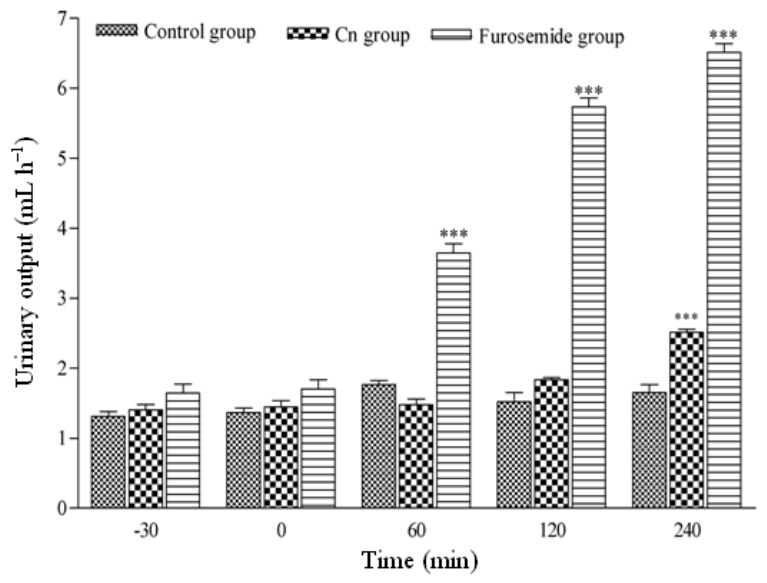

Fig. 3: Effect of intravenous administration of aqueous $\mathrm{Cn}$ extract $\left(500 \mathrm{mg} \mathrm{kg}^{-1} \mathrm{~h}^{-1}\right)$ on urinary excretion of water $\left(\mathrm{mL} \mathrm{h}^{-1}\right)$. Data are expressed as means \pm SEM, $\mathrm{n}=6$ rats per group. $* *$ : $\mathrm{p}<0.01, \quad \mathrm{p}<0.001$ when compared to the respective control values

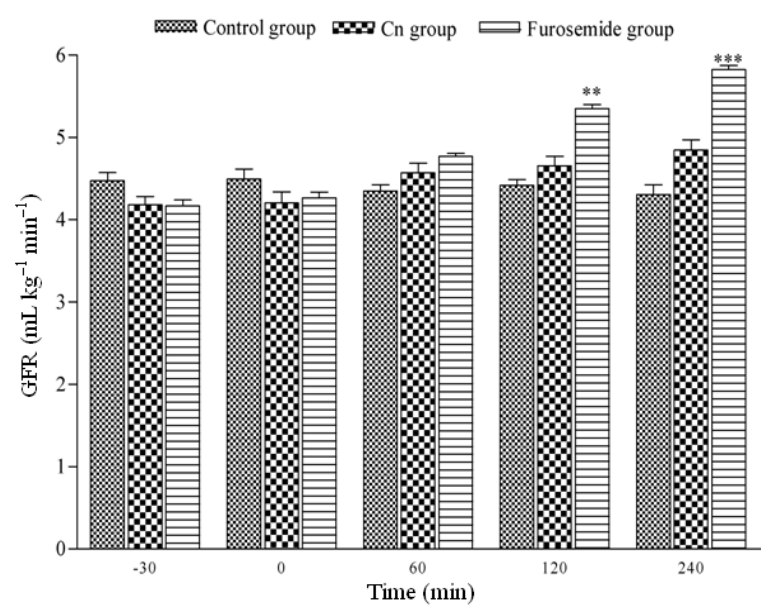

Fig. 4: Effect of intravenous administration of aqueous Cn extract $\left(500 \mathrm{mg} \mathrm{kg}^{-1} \mathrm{~h}^{-1}\right)$ on glomerular Filtration Rate (GFR) $\left(\mathrm{mL}^{-1} \mathrm{~kg}^{-1} \mathrm{~h}^{-1}\right)$. Data are expressed as means \pm SEM, $n=6$ rats per group. $* *: p<0.01, p<0.001$ when compared to the respective control values

Effect on Glomerular Filtration Rate (GFR): No significant change in GFR was observed after intravenous perfusion on $\mathrm{CN}$ at a dose of $200 \mathrm{mg} \mathrm{kg}^{-1} \mathrm{~h}^{-1}(\mathrm{p}>0.05)$. Furosemide treated group showed significant increase in GFR after two hours of intravenous perfusion $(p<0.01)$. Additional increase was observed at the end of experiments $(p<0.001)$ (Fig. 4). 


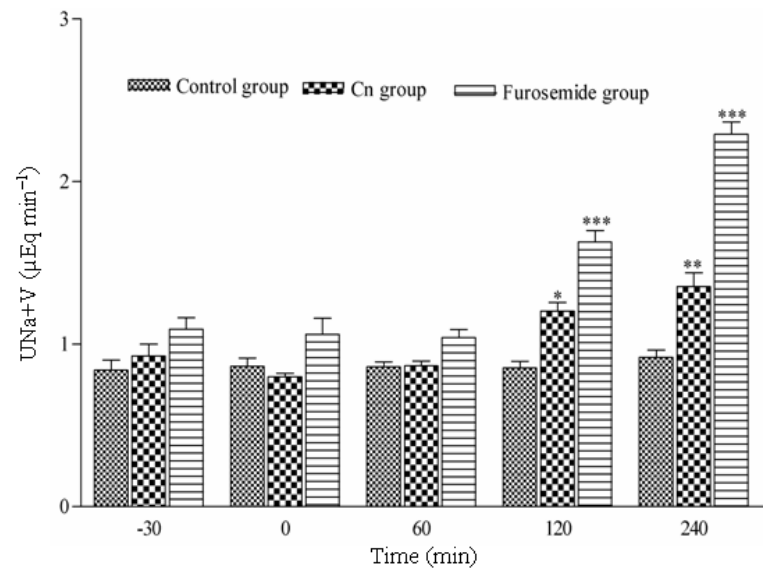

Fig. 5a: Effect of intravenous administration of aqueous $\mathrm{Cn}$ extract $\left(500 \mathrm{mg} \mathrm{kg}^{-1} \mathrm{~h}^{-1}\right)$ on urinary excretion of sodium $(\mathrm{UNa}+\mathrm{V})\left(\mu \mathrm{Eq} \mathrm{min}^{-1}\right)$. Data are expressed as means \pm SEM, $\mathrm{n}=6$ rats per group. ${ }^{* *}: \mathrm{p}<0.01, \mathrm{p}<0.001$ when compared to the respective control values

Effect on urinary sodium excretion: Figure 5a shows changes in urinary electrolytes excretion after intravenous perfusion of $\mathrm{Cn}$ aqueous extract. When perfused at a dose of $200 \mathrm{mg} \mathrm{kg}^{-1} \mathrm{~h}^{-1}, \mathrm{Cn}$ aqueous extract produced a significant increase in the urinary sodium excretion after two hours of perfusion $(p<0.001)$. Additional one hour perfusion did not cause further increase in urinary sodium excretion. Furosemide perfusion when perfused at a dose of 0.1 $\mathrm{mg} \mathrm{kg}{ }^{-1} \mathrm{~h}^{-1}$ produced significant and sustained increase in urinary sodium excretion from the first to the third hour of perfusion.

Effect on urinary potassium excretion: In Fig. 5b, intravenous perfusion of $\mathrm{Cn}$ aqueous extract at a dose of $200 \mathrm{mg} \mathrm{kg}^{-1} \mathrm{~h}^{-1}$ caused a significant increase in urinary potassium excretion after two $(\mathrm{p}<0.05)$ and three $(p<0.01)$ hours of intravenous perfusion. Furosemide perfusion produced significant increase in urinary potassium escretion from the first hour $(\mathrm{p}<0.05)$ to the third hour $(\mathrm{p}<0.001)$.

Effect on urinary chlorure excretion: Figure 5c shows the time evolution of urinary chlorure excretion. Intravenous injection of $\mathrm{Cn}$ aqueous extract caused a significant increase two hours after the start of perfusion $(p<0.001)$ no additional increase was observed at the third hour of perfusion $(p<0.001)$. Significant increase in urinary chlorure excretion was observed after one hour $(\mathrm{p}<0.001)$ in furosemide perfused group $(\mathrm{p}<0.001)$.

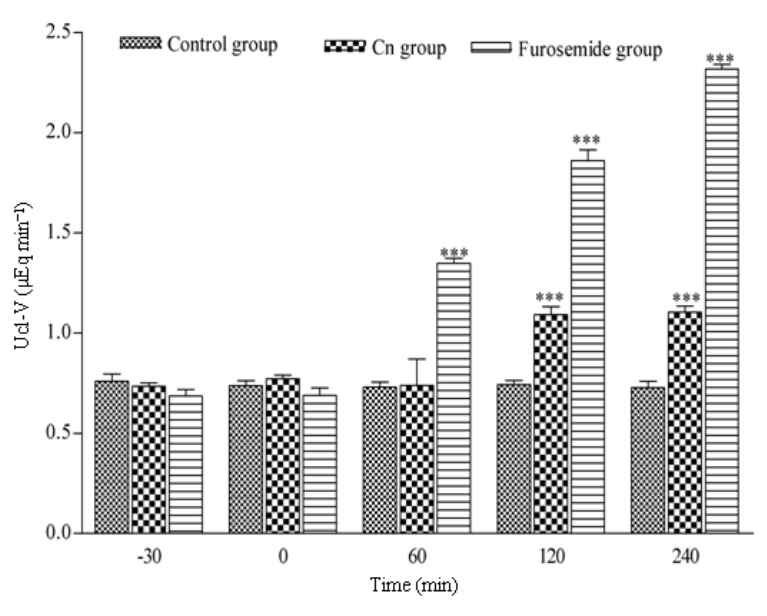

Fig. 5c: Effect of intravenous administration of aqueous $\mathrm{Cn}$ extract $\left(500 \mathrm{mg} \mathrm{kg}^{-1} \mathrm{~h}^{-1}\right)$ on urinary excretion of chlorure (Ucl-V) $(\mu \mathrm{Eq}$ $\left.\min ^{-1}\right)$. Data are expressed as means \pm S.E.M, $\mathrm{n}=6$ rats per group. $* * \mathrm{p}<0.01, \mathrm{p}<0.001$ when compared to the respective control values

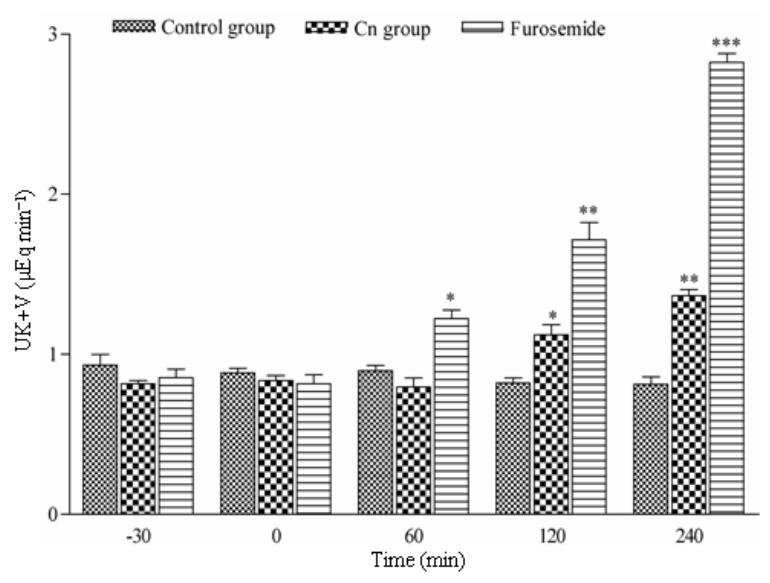

Fig. 5b: Effect of intravenous administration of aqueous $\mathrm{Cn}$ extract $\left(500 \mathrm{mg} \mathrm{kg}^{-1} \mathrm{~h}^{-1}\right)$ on urinary excretion of potassium $(\mathrm{UK}+\mathrm{V})$ $\left(\mu \mathrm{Eq} \min ^{-1}\right)$. Data are expressed as means \pm SEM, $\mathrm{n}=6$ rats per group. ${ }^{* *}: \mathrm{p}<0.01$, $\mathrm{p}<0.001$ when compared to the respective control values

\section{DISCUSSION}

$\mathrm{Cn}$ is world wildly used in the treatment of various diseases ${ }^{[17]}$. Our previous works demonstrated the potent hypoglycaemic effect of $\mathrm{Cn}$ aqueous extract in streptozotocin-induced diabetic rats ${ }^{[18]}$. This work was carried out to evaluate the hypotensive and diuretic of 
intravenous injection of $\mathrm{Cn}$ aqueous extract. $\mathrm{Cn}$ aqueous extract was lyophilized and injected intravenously in bolus mode at a dose of 50, 100 and $200 \mathrm{mg} \mathrm{kg}^{-1}$ of body weight and arterial blood pressure was monitored via a catheter placed in the carotid artery. In spite of same disadvantages, the used method of blood pressure measurement was largely used in the screening of cardiovascular effect of drugs ${ }^{[19]}$. The intravenous injection of $\mathrm{Cn}$ aqueous exract produce a dose dependent reduction in arterial blood pressure. The duration of the hypotensive effect was lasted after 5 min of the intravenous injection. Previous studies have established the hypotensive effect of plant extract after intravenous injection ${ }^{[20-23]}$. Furthermore, $\mathrm{Cn}$ aqueous extract produced significant reduction in heart frequency, so $\mathrm{Cn}$ aqueous extract may reduce arterial pressure via at least a reduction in heart rate ${ }^{[23]}$. However, it is not exclude that the $\mathrm{Cn}$ aqueous extract may act affect the adrenergic system to reduce vascular tone ${ }^{[21,23,24]}$. The rapid unset of arteial pressure reduction leads us to postulate the probable inplication of sympathic or cholinergic system in the hypotensive effect of $\mathrm{Cn}$ aqueous extract. In normal rats blood pressure is strictly controled via a complex nervous and hormonal function ${ }^{[25]}$, the observed reduction in the arterial blood pressure witness the strong hypotensive effect of $\mathrm{Cn}$ aqueous extract.

In the second part of this study, $\mathrm{Cn}$ aqueous extract was perfused intravenously at a rate of $200 \mathrm{mg} \mathrm{kg}^{-1} \mathrm{~h}^{-1}$, urine volume and electrolytes were measured in order to evaluate the renal effect of $\mathrm{CN}$ aqueous extract. Furosemide, a loop diuretic agent, was used as a reference $\operatorname{drug}^{[26]}$. We demonstrated that the $\mathrm{Cn}$ increases diuresis. Furthemore, sodium, potassium and chlorure urinary excretion was increased. Previous studies demonstrated diuretic activity of medicinal plants ${ }^{[9,13,26-31]}$. The increase in urinary electrolytes may be probably due to the inhibition of renal $\mathrm{Na}+-\mathrm{K}+$ pump that would lead to a reduction in $\mathrm{Na}+$ and $\mathrm{K}+$ reabsorption leading thus to an osmotic water flow into the lumen and diuresis ${ }^{[13]}$. Plant mineral content may probably increase urinary and electrolytes excretion ${ }^{[32]}$. $\mathrm{Cn}$ did not produce renal artery vasodilatation since GFR was unchanged during perfusion, previous studies have been reported the increase of GFR in parallel with increasing diuresis ${ }^{[15,31]}$. It is well established that increasing diuresis and electrolytes excretion may reduce arterial blood pressure ${ }^{[13,20,23,26]}$. Thus, Cn aqueous extract may reduce blood pressure after chronic administration.

Photochemical investigation reported the abundance of flavonoid product in $\mathrm{Cn}^{[33]}$. Flavonoids possess beneficial cardiovascular effect and may be thus responsible of the observed hypotensive and diuretic effect ${ }^{[34]}$.
We conclude the $\mathrm{Cn}$ aqueous extract possess a dose dependent hypotensive and diuretic effects when administered intravenously.

\section{REFERENCES}

1. Rates, S.M.K., 2001. Plants as source of drugs. Toxicon, 39: 603-613.

2. Gurib-Fakim, A., 2006. Medicinal plants: Traditions of yesterday and drugs of tomorrow. Mol. Aspect. Med., 1: 1-93.

3. Bellakhdar, J., R. Claisse, J. Fleurentin and C. Younos, 1991. Repertory of standard herbal drugs in the Moroccan pharmacopoea. J. Ethnopharmacol., 2: 123-143.

4. Eddouks, M., M. Maghrani, A. Lemhadri, M.L. Ouahidi and H. Jouad, 2002. Ethnopharmacological survey of medicinal plants used for the treatment of diabetes mellitus, hypertension and cardiac diseases in the south-east region of Morocco (Tafilalet). J. Ethnopharmacol., 2-3: 97-103.

5. Tahraoui, A., J. El-Hilaly, Z.H. Israili and B. Lyoussi, 2007. Ethnopharmacological survey of plants used in the traditional treatment of hypertension and diabetes in south-eastern Morocco (Errachidia province). J. Ethnopharmacol., 1: 105-117.

6. McVeigh, G., J. Flack and R. Grimm, 1995. Goals of antihypertensive therapy. Drugs, 2: 161-75.

7. Tahri, A., S. Yamani, A. Legssyer, M. Aziz, H. Mekhfi, M. Bnouham and A. Ziyyat, 2000. Acute diuretic, natriuretic and hypotensive effects of a continuous perfusion of aqueous extract of Urtica dioica in the rat. J. Ethnopharmacol., 1-2: 95.

8. Sripanidkulchai, B., V. Wongpanich, P. Laupattarakasem, J. Suwansaksri and D. Jirakulsomchok, 2001. Diuretic effects of selected Thai indigenous medicinal plants in rats. J. Ethnopharmacol., 2-3: 185-190.

9. Ratnasooriya, W.D., K.P.P. Pieris, U. Samaratunga and J.R. Jayakody, 2004. Diuretic activity of Spilanthes acmella flowers in rats. J. Ethnopharmacol., 2-3: 317-320.

10. Pantoja, C.V., B.C. Norris and C.M. Contreras, 1996. Diuretic and natriuretic effects of chromatographically purified fraction of garlic (Allium sativum). J. Ethnopharmacol., 2: 101-105.

11. Occhiuto, F., C. Circosta, S. Ragusa, P. Ficarra and R. Costa De Pasquale, 1985. A drug used in traditional medicine: Harpagophytum procumbens DC. IV. effects on some isolated muscle preparations. J. Ethnopharmacol., 2: 201-208. 
12. Lahlou, S., A. Tahraoui, Z. Israili and B. Lyoussi, 2007. Diuretic activity of the aqueous extracts of Carum carvi and Tanacetum vulgare in normal rats. J. Ethnopharmacol., 110: 458-463.

13. Kreydiyyeh, S.I. and J. Usta, 2002. Diuretic effect and mechanism of action of parsley. J. Ethnopharmacol., 3: 353-357.

14. Jouad, H., M.A. Lacaille-Dubois and M. Eddouks, 2001. Chronic diuretic effect of the water extract of Spergularia purpurea in normal rats. J. Ethnopharmacol., 2-3: 219-225.

15. Maghrani, M., N.A. Zeggwagh, J.B. Michel and M. Eddouks, 2005. Antihypertensive effect of Lepidium sativum L. in spontaneously hypertensive rats. J. Ethnopharmacol., 1-2: 193-197.

16. Eddouks, M., M. Maghrani, N.A. Zeggwagh, M. Haloui and J.B. Michel, 2005. Fraxinus excelsior L. evokes a hypotensive action in normal and spontaneously hypertensive rats. J. Ethnopharmacol., 1: 49-54.

17. Konig, G.M., A.D. Wright, W.J. Keller, R.L. Judd, S. Bates and C. Day, 1998. Hypoglycaemic activity of an HMG-containing flavonoid glucoside, chamaemeloside, from Chamaemelum nobile. Planta Med., 7: 612-614.

18. Eddouks, M., A. Lemhadri, N.A. Zeggwagh and J.B. Michel, 2005. Potent hypoglycaemic activity of the aqueous extract of Chamaemelum nobile in normal and streptozotocin-induced diabetic rats. Diabetes Res. Clin. Pract., 3: 189-195.

19. Kurtz, T.W., K.A. Griffin, A.K. Bidani, R.L. Davisson and J.E. Hall, 2005. Recommendations for blood pressure measurement in humans and experimental animals. Part 2: Blood pressure measurement in experimental animals: A statement for professionals from the subcommittee of professional and public education of the American Heart Association council on high blood pressure research. Hypertension, 2: 299-310.

20. Zhang, C.Y. and B.K.H. Tan, 1997. Mechanisms of cardiovascular activity of Andrographis paniculata in the anaesthetized rat. J. Ethnopharmacol., 2: 97-101.

21. Villar, A., M. C. Terencio and M. Paya, 1986. Hypotensive effect of Rhamnus lycioides extracts. J. Ethnopharmacol., 2-3: 269-273.

22. Poli, A., M. Nicolau, C.M. Oliveira Simoes, R.M. Ribeiro-do-Valle Nicolau and M. Zanin, 1992. Preliminary pharmacologic evaluation of crude whole plant extracts of Elephantopus scaber. Part I: In vivo studies. J. Ethnopharmacol., 1: 71-76.
23. Mok, J.S.L., P. Chang, K.H. Lee, T.S. Kam and S. H. Goh, 1992. Cardiovascular responses in the normotensive rat produced by intravenous injection of gambirine isolated from Uncaria callophylla $\mathrm{Bl}$. ex Korth. J. Ethnopharmacol., 3: 219-223.

24. Sharma, R., V. Ahuja and M. Fahim, 2004. Effects of alpha-1 adrenergic receptor antagonist, terazosin, on cardiovascular functions in anaesthetised dogs. Indian J. Exp. Biol., 2: 1195-1199.

25. Cowley, A.W., 1984. long-term control of arterial blood pressure. Physiology, 72: 231-300.

26. Lahlou, S., A. Tahraoui, Z. Israili and B. Lyoussi, 2007. Diuretic activity of the aqueous extracts of Carum carvi and Tanacetum vulgare in normal rats. J. Ethnopharmacol., 3: 458-463.

27. Caceres, A., L.M. Giron and A.M. Martinez, 1987. Diuretic activity of plants used for the treatment of urinary ailments in guatemala. J. Ethnopharmacol., 3: 233-245.

28. De Ribeiro, R., F. de Barros, M.M.R.F. de Melo, C. Muniz, S. Chieia, M. das Gracas Wanderley, C. Gomes and G. Trolin, 1988. Acute diuretic effects in conscious rats produced by some medicinal plants used in the state of Sao Paulo, Brasil. J. Ethnopharmacol., 1: 19-29.

29. Hattori, T. and P.L. Wang, 2006. Involvement of $\mathrm{Na}(+)-\mathrm{K}(+)-2 \mathrm{Cl}(-)$ cotransporters in hypertonicityinduced rise in intracellular calcium concentration. Int. J. Neurosci., 12: 1501-1507.

30. Jouad, H., M.A. Lacaille-Dubois and M. Eddouks, 2001. Chronic diuretic effect of the water extract of Spergularia purpurea in normal rats. J. Ethnopharmacol., 2-3: 219-223.

31. Maghrani, M., N.A. Zeggwagh, M. Haloui and M. Eddouks, 2005. Acute diuretic effect of aqueous extract of Retama raetam in normal rats. J. Ethnopharmacol., 1: 31-35.

32. Szentmihlyi, 1998. Potassium-sodium ratio for the characterization of medicinal plant extracts with diuretic activity. Phytotherap. Res., 3: 163-166.

33. Ma, C.M., L. Winsor and M. Daneshtalab, 2007. Quantification of spiroether isomers and herniarin of different parts of Matricaria matricarioides and flowers of Chamaemelum nobile. Phytochem. Anal., 1: 42-49.

34. Jouad, H., M.A. Lacaille-Dubois, B. Lyoussi and M. Eddouks, 2001. Effects of the flavonoids extracted from Spergularia purpurea Pers. on arterial blood pressure and renal function in normal and hypertensive rats. J. Ethnopharmacol., 2: $159-63$. 